\title{
PENGEMBANGAN MEDIA PEMBELAJARAN BERBASIS VIRTUAL REALITY UNTUK MENINGKATKAN HASIL BELAJAR PESERTA DIDIK SEKOLAH DASAR
}

\author{
Mardiki Supriadi $^{1}$, L. Virginayoga Hignasari ${ }^{2}$
}

\author{
${ }^{12}$ Universitas Mahendradatta, Denpasar,Bali \\ Email: ${ }^{1}$ mardiki@yahoo.co.id, ${ }^{2}$ ginahignasari@gmail.com
}

\begin{abstract}
Abstrak
Pendidik menggunakan berbagai macam metode untuk menjelaskan materi agar tujuan pembelajaran dapat tercapai, salah satu metodenya dengan memanfaatkan media pembelajaran. Tujuan menggunakan media pembelajaran dalam kegiatan pembelajaran yakni untuk memudahkan komunikasi dan belajar. Pemanfaatan media dalam kegiatan pembelajaran bertujuan agar menarik perhatian peserta didik dan memperkuat konsentrasi mereka pada saat menerima materi dari pendidik.Pengembangan media virtual reality merupakan salah satu usaha untuk mewujudkan tujuan pendidikan. Kesuksesan sebuah pembelajaran salah satunya terletak pada kemampuan hasil belajar peserta didik. Hasil belajar sangat penting bagi peserta didik sebagai tolak ukur sejauh mana pe serta didik memahami materi telah disampaikan pendidik. Media virtual reality menjadikan hasil belajar sebagai dasar pengembangan. Tujuan penelitian ini adalah menghasilkan produk berupa media virtual reality untuk meningkatkan hasil belajar peserta didik sekolah dasar.Penelitian ini merupakan penelitian pengembangan dengan model pengembangan 4D dari Thiagarajan. Model pengembangan ini terdiri atas tahap define (pendefinisian), design (perancangan), develop (pengembangan), dan disseminate (penyebaran). Tahap penelitian dan pengembangan dilaksanakan sampai tahap disseminate dengan publikasi artikel dan proses uji coba kepada peserta didik yang dilakukan secara terbatas. Instrumen pengumpulan data berupa angket yang disebarkan kepada ahli materi, media, dan penerapan lapangan.Hasil belajar peserta didik kelas eksperimen dan kelas kontrol dapat diambil kesimpulan bahwa media pembelajaran berbasis virtual reality yang digunakan pada kelas eksperimen dinyatakan lebih efektif dan dapat meningkatkan hasil belajar peserta didik dengan persentase sebesar $100 \%$ sedangkan pada kelas kontrol memperoleh $77,3 \%$.
\end{abstract}

Kata kunci: media pembelajaran, virtual reality, hasil belajar

\begin{abstract}
Educators use various methods to explain the material so that learning objectives can be achieved, one of the methods is by utilizing learning media. The purpose of using learning media in learning activities is to facilitate communication and learning. The use of media in learning activities aims to attract the attention of students and strengthen their concentration when receiving material from educators. The development of virtual reality media is an effort to realize educational goals. One of the success of learning lies in the ability of students' learning outcomes. Learning outcomes are very important for students as a benchmark of the extent to which students understand the material delivered by educators. Virtual reality media make learning outcomes the basis of development. The purpose of this study is to produce products in the form of virtual reality media to improve learning outcomes of elementary school students.This research is a development research with $4 D$ development model from Thiagarajan. This development model consists of the stages define (design), design (design), develop (development), and disseminate (deployment). The research and development stage is carried out until the disseminate stage with the publication of articles and a trial process to students which is done on a limited basis. Data collection instruments in the form of a questionnaire distributed to experts in the material, media, and field application.Student learning outcomes of the experimental class and the control class can be concluded that the virtual reality-based learning media used in the experimental class are stated to be more effective and can improve student learning outcomes by a percentage of $100 \%$ while the control class gets $77.3 \%$.
\end{abstract}

Keywords: learning media, virtual reality, learning outcomes

\section{PENDAHULUAN}

Perkembangan ilmu pengetahuan dan teknologi saat ini mempengaruhi perkembangan bidang-bidang keilmuan yang lain seperti halnya bidang pendidikan. Perkembangan dalam pendidikan dapat terlihat dari adanya perubahanperubahan komponen yang ada didalamnya seperti kualitas pendidik, kurikulum, proses pembelajaran, sarana dan prasarana pembelajaran, sumber belajar, dan lain-lain. Potret pendidikan yang terjadi dalam lingkungan sekolah tidak hanya terlihat sebagai kegiatan guru mengajar dan siswa belajar, tetapi merupakan sebuah proses kegiatan belajar mengajar dimana seorang pendidik dan peserta didik harus bekerjasama dalam menciptakan suasana belajar yang mendukung tujuan pendidikan sesuai dengan tuntutan kurikulum. Menurut Akbar (2013) menyatakan bahwa pembelajaran akan berjalan secara efektif apabila guru mampu memanfaatkan sumber dan media pembelajaran. Guru dituntut supaya dapat memanfaatkan kemajuan teknologi guna menunjang pembelajaran, sedangkan peserta didik diharapkan agar terlibat aktif dalam memecahkan permasalahan-permasalahan yang dihadapinya.

Teknologi saat ini berperan penting dalam kegiatan pembelajaran, salah satunya di tingkat pendidikan dasar. Teknologi mampu memberikan kemudahan dalam segala hal, akan tetapi pada kenyataannya di lingkungan sekolah dasar di provinsi Bali teknologi masih belum dimanfaatkan secara maksimal. Berikut fakta dilapangan terkait dengan kegiatan pembelajaran di tingkat sekolah dasar: (a) kurang maksimalnya dalam menyampaikan materi yang sangat sulit untuk dihadirkan di dalam kelas; (b) belum tersedia media pembelajaran yang dapat memfasilitasi karakteristik peserta didik saat ini; (c) kurang maksimal dalam memanfaatkan teknologi yang lebih modern dan sesuai dengan gaya belajar peserta didik saat ini.

Fakta-fakta tersebut seolah memberikan kewajiban pada seorang pendidik untuk dengan teliti dan tepat dalam menggunakan media pembelajaran yang dapat membantu peserta pada saat kegiatan pembelajaran. Permasalahan- 
permasalahan yang telah dipaparkan di atas dapat menyimpulkan bahwa para pendidik sekolah dasar membutuhkan media pembelajaran yang dapat membantu pendidik dalam menjelaskan materi yang susah untuk menghadirkannya di dalam kelas. Pendidik juga membutuhkan media pembelajaran yang dapat meningkatkan hasil belajar serta menarik bagi peserta didik serta sesuai dengan keinginan belajar peserta didik yang saat ini lebih menyukai belajar dengan memanfaatkan tab atau smartphone dari pada media pembelajaran yang lain. Selain itu, pengembangan media pembelajaran yang dibutuhkan tidak hanya mengandung unsur visual akan tetapi juga mengandung unsur audio.

Berdasarkan permasalahan-permasalahan yang sudah dipaparkan tersebut. Peneliti memberikan solusi dengan pengembangkan sebuah media pembelajaran yang dapat mengatasi permasalahan-permasalahan yang sudah dipaparkan. Media pembelajaran tersebut berupa media dengan format Virtual Reality (VR), yang dapat membantu pendidik untuk menjelaskan materi tata surya pada saat kegiatan pembalajaran. Virtual reality mengacu pada penggunaan simulasi interaktif untuk pengguna dengan kesempatan untuk terlibat dalam lingkungan yang mungkin tampak dan terasa serupa dengan benda dan peristiwa dunia nyata dan itu mungkin menimbulkan perasaan hadir di dunia maya (Ghali et al., 2012).

Virtual reality juga merupakan teknologi yang ampuh untuk memecahkan masalah dunia nyata saat ini. Untuk tujuan pendidikan pada umumnya, virtual reality telah banyak diusulkan sebagai terobosan teknologi yang signifikan yang memiliki potensi besar untuk memfasilitasi pembelajaran (Sun, Lin, \& Wang, 2010). Salah satu manfaat menggunakan virtual reality yakni berpotensi mendorong retensi belajar peserta didik (Chou, 2017). Media virtual reality selain mengandung unsur visual juga mengandung unsur audio.

Model penelitian yang digunakan pada penelitian ini ialah model 4D dari Thiagarajan, Semmel dan Semmel (1974). Model 4D ini terdiri dari empat tahapan, yakni define (pendefinisian), design (perancangan), develop (pengembangan), dan disseminate (penyebaran). Penelitian ini dilakukan sampai tahap disseminate dengan proses uji lapangan yang dilakukan secara terbatas.

Alasan peneliti menggunakan model 4D untuk penelitian ini karena dari segi tahapan model 4D tergolong sistematis serta sesuai dengan tahapan-tahapan dalam mengembangkan media pembelajaran. Tahapan-tahapan model 4D dapat memberikan arahan yang jelas dalam mengembangkan sebuah media pembelajaran. Dalam model 4D terdapat tahapan-tahapan khusus dalam mengembangkan media pembelajaran, sistematis, serta lebih rinci. Dengan demikian pengembangan media pembelajaran mendapatkan hasil yang maksimal.

\section{METODE PENELITIAN}

Metode penelitian dan pengembangan menggunakan model pengembangan 4D (Thiagarajan, S., Semmel, D.,Semmel, M.I., 1974). Model pengembangan ini meliputi empat tahapan dan keempat tahapan tersebut dijelaskan berikut ini.

1. Define

Tahap ini berfungsi mendefinisikan dan menetapkan kepentingan pembelajaran dengan cara mengkaji tujuan serta batasan terhadap konsep pada pembelajaran sekolah dasar yakni sesuai dengan komptensi dasar yang tertera pada tema. Tahap define juga mempunyai beberapa tahapan yakni: (a) Front-end Analysis (analisis awal dan akhir), (b) Learner Analysis (analisis pebelajar), (c) Concept Analysis (analisis konsep), (d) Task Analysis (analisis tugas), serta (e) Specifying Instructional Objectives (tujuan pembelajaran).

2. Design

Tahap ini bertujuan untuk merancang prototype media virtual reality. Pada tahap ini mempunyai empat langkah, yakni sebagai berikut: (a) Constructing Criterion-Referenced Test (penyusunan tes kriteria), (b) Media Selection (pemilihan media), (c) Format Selection (format media), dan (d) Initial Design (merancang awal).

3. Develop

Tahap ini bertujuan untuk menghasilkan sebuah produk yang akan dikembangkan. Berikut tahapan pengembangan yang dilalukan: pertama expert appraisal (penilaian para ahli) dengan proses revisi; dan tahapan kedua developmental testing (uji coba pengembangan). Tahapan ini bertujuan untuk menghasilkan final draft (draft akhir). Berikut tahapan dalam proses pengembangan produk.

a. Expert Appraisal

Tahap ini bertujuan untuk menguji kevalidan produk yang dikembangkan. Tahap validasi ahli yang dilakukan akan menghasilkan data berupa penilaian, masukan dan kritikan dari para validator. Tahapan yang dilakukan yakni berdiskusi dan menyerahkan produk yang dikembangkan sesuai dengan acuan desain media, materi dan penerapan lapangan kepada para ahli (validator).

b. Developmental Testing

Tahap ini bertujuan untuk mendapatkan masukan langsung berupa penilaian dan komentar peserta didik terhadap produk yang dikembangkan. Tahapan yang akan dilalui diantaranya uji coba produk setelah itu melakukan revisi berdasarkan masukan tanggapan, kritik dan saran. Uji coba produk mempunyai tahapan yakni uji coba perorangan, kelompok kecil, kelompok besar serta lapangan.

c. Disseminate 
Tahap ini dalam penelitian pengembangan dilakukan melalui kegiatan penyebaran produk yang dikembangkan dengan disebarkan dalam ruang lingkup kecil yakni pada lokasi penelitian pada saat uji coba lapangan.

\section{HASIL DAN PEMBAHASAN}

Pengembangan yang dilakukan menghasilkan produk berupa media pembelajaran berbasis virtual reality. Media pembelajaran ini disajikan dalam bentuk aplikasi android yang dapat dipasang dan dibuka pada smartphone yang berbasis android. Media ini menyajikan materi tata surya pembelajaran Ilmu Pengetahuan Alam. Materi yang disajikan terfokus pada matahari dan planet-planet. Materi ini dikemas ke dalam bentuk virtual reality yang dapat memberikan kesan pada pengguna media ini seolah-olah dapat melihat langsung objek seperti matahari dan planetplanet yang berada diluar angkasa. Untuk melihat objek-objek tersebut dapat dilakukan dengan VR Box. Aplikasi ini berisi beberapa menu yang dapat dipilih oleh penggunanya.Validasi ahli media pada media pembelajaran berbasis virtual reality terdiri dari 21 aspek. Hasil validasi oleh ahli media yakni 82\% atau Sangat Valid. Validasi ahli materi pada media pembelajaran berbasis virtual reality terdiri dari 5 aspek. Hasil validasi oleh ahli materi yakni $80,5 \%$ atau Sangat Valid. Validasi ahli penerapan lapangan terhadap media pembelajaran berbasis virtual reality terdiri dari 3 aspek. Hasil validasi oleh ahli penerapan lapangan yakni 88,8\% atau Sangat Valid.Tahap pertama dalam uji coba produk media yang dikembangkan adalah tahap uji coba perorangan. Pelaksanaan uji coba perorangan dilakukan pada dua orang peserta didik. Dua orang peserta didik mewakili gender yang pada kelas tersebut yakni satu orang peserta didik laki-laki dan satu orang peserta didik perempuan. Tujuan dari pelaksanaan uji coba ini yakni untuk melihat tingkat kemenarikan dan kepraktisan media yang dikembangkan. Berikut persentase hasil uji coba perorangan yang telah dianalisis, dapat dilihat pada tabel 1.

Tabel 1. Hasil Respon Peserta Didik pada Uji Coba Perorangan

\begin{tabular}{clcl}
\hline No. & \multicolumn{1}{c}{ Aspek Yang Dinilai } & Rata-rata $(\boldsymbol{\%})$ & Keterangan \\
\hline 1 & Kemenarikan Media & $90,6 \%$ & Sangat Valid \\
2 & Kepraktisan Media & $87,5 \%$ & Sangat Valid \\
\hline
\end{tabular}

Tahap kedua dalam uji coba produk media yang dikembangkan yakni tahap uji coba kelompok kecil. Pelaksanaan uji coba kelompok kecil dilaksanakan pada enam orang peserta didik. Enam orang peserta didik mewakili gender yang pada kelas serta mewakili kemampuan kognitif peserta didik tersebut yakni tiga orang peserta didik lakilaki dan tiga orang peserta didik perempuan. Tiga orang peserta didik laki-laki mewakili tingkat kognitif mereka yakni tingkat tinggi, menengah dan rendah. Begitu juga dengan tiga orang peserta didik perempuan yang juga mewakili tingkat kemampuan kognitif tinggi, menengah dan rendah. Tujuan dari pelaksanaan uji coba ini yakni untuk melihat tingkat kemenarikan serta kepraktisan media. Berikut persentase hasil uji coba kelompok kecil yang telah dianalisis, dapat dilihat pada tabel 2.

Tabel 2. Hasil Respon Peserta Didik pada Uji Coba Kelompok Kecil

\begin{tabular}{clcl}
\hline No. & Aspek Yang Dinilai & Rata-rata $(\boldsymbol{\%})$ & Keterangan \\
\hline 1 & Kemenarikan Media & $83,3 \%$ & Sangat Valid \\
2 & Kepraktisan Media & $80,5 \%$ & Sangat Valid \\
\hline
\end{tabular}

Tahap ketiga dalam uji coba produk media yang dikembangkan adalah tahap uji coba kelompok besar. Pelaksanaan uji coba kelompok besar dilaksanakan pada seluruh peserta didik. Tujuan dari pelaksanaan uji coba ini yakni untuk melihat tingkat kemenarikan serta kepraktisan media. Berikut persentase hasil uji coba kelompok besar yang telah dianalisis, dapat dilihat pada tabel 3.

Tabel 3. Hasil Respon Peserta Didik pada Uji Coba Kelompok Besar

\begin{tabular}{clcl}
\hline No. & \multicolumn{1}{c}{ Aspek Yang Dinilai } & Rata-rata (\%) & Keterangan \\
\hline 1 & Kemenarikan Media & $84,2 \%$ & Sangat Valid \\
2 & Kepraktisan Media & $80,6 \%$ & Sangat Valid \\
\hline
\end{tabular}

Hasil belajar peserta didik kelas eksperimen dan kelas kontrol dapat dilihat pada tabel 4. yang disampaikan sebagai berikut berikut.

Tabel 4. Persentase Hasil Belajar Kelas Eksperimen dan Kontrol

\begin{tabular}{clcc}
\hline No & \multicolumn{1}{c}{ Kelas } & Rata-rata & Keterangan \\
\hline 1 & Kelas Eksperimen & $100 \%$ & Sangat Baik \\
2 & Kelas Kontrol & $77,3 \%$ & Baik \\
\hline
\end{tabular}

Hasil belajar peserta didik kelas eksperimen dan kelas kontrol dapat diambil kesimpulan bahwa media pembelajaran berbasis virtual reality yang digunakan pada kelas eksperimen dinyatakan lebih efektif dan dapat 
meningkatkan hasil belajar peserta didik dengan persentase sebesar $100 \%$ sedangkan pada kelas kontrol memperoleh $77,3 \%$.

\section{KESIMPULAN}

Media pembelajaran berbasis virtual reality ini dapat meningkatkan hasil belajar peserta didik karena media yang dikembangkan ini terdapat unsur visual untuk penglihatan serta audio untuk pendengaran.

Kelebihan media pembelajaran berbasis virtual reality yang dikembangkan antara lain sebagai berikut.

1. Media pembelajaran berbasis virtual reality ini mempunyai tampilan yang sangat menarik dan merupakan aplikasi yang terbaru dalam bidang IT.

2. Media pembelajaran berbasis virtual reality ini disajikan dalam bentuk virtual reality sehingga materi tata surya yakni matahari dan planet-planet dapat dilihat langsung oleh pengguna sehingga peserta didik pada saat kegiatan pembelajaran tidak membayangkan bentuk dari matahari dan planet akan tetapi peserta didik dapat langsung melihat bentuknya.

3. Media pembelajaran berbasis virtual reality ini mempunyai tingkat validitas yang sangat tinggi dan memenuhi syarat untuk dipergunakan pada saat kegiatan pembelajaran pada konsep matahari dan plant. Tingkat validitas ini diperoleh dari hasil uji vailiditas beberapa ahli yakni ahli media pembelajaran, ahli materi pembelajaran dan ahli penerapan lapangan serta dilanjutkan dengan uji coba produk pada uji coba perorangan, uji coba kelompok kecil, dan uji coba kelompok besar.

4. Media pembelajaran berbasis virtual reality ini dapat meningkatkan hasil belajar peserta didik terhadap materi atau konsep yang dipelajari saat kegiatan pembelajaran berdasarkan uji coba lapangan yang dilakukan peneliti.

\section{REFERENCES}

[1] Akbar, S. 2013. Instrumen Perangkat Pembelajaran. Bandung: PT Remaja Rosdakarya.

[2] Alghamdi, A. \& Kingdom, U. 2015. An Investigation of Saudi Teachers ' Attitudes Towards IWBS and Their Use for Teaching and Learning in Yanbu. , 8(6), 539-554.

[3] Anderson, L.R. \& Kratwohl, D.R. 2001. A Taxonomy for Learning, Teaching, and Assesing: A Revision of Bloom's Taxonomy of Eductional Objectives. A Bridged Edition. New York: Addision Wesley Longman, Inc.

[4] Chou, C.C. 2017. An Analysis of The 3D Video and Interactive Response Approach Effects on The Science Remedial Teaching for Fourth Grade Underachieving Students. Eurasia Journal of Mathematics, Science and Technology Education, 13(4), 1059-1073. https://doi.org/10.12973/eurasia.2017.00658a.

[5] Ghali, N.I., Soluiman, O., El-Bendary, N., Nassef, T.M., Ahmed, S.A., Elbarawy, Y.M. \& Hassanien, A.E. 2012. Virtual Reality Technology for Blind and Visual Impaired People: Reviews and Recent Advances. Intelligent Systems Reference Library, 26, 363-385. https://doi.org/10.1007/978-3-642-23363-0_15.

[6] González, M.M.A., Santos, B.S.N., Vargas, A.R., Martín-Gutiérrez, J. \& Orihuela, A.R. 2013. Virtual Worlds. Opportunities and Challenges in The 21st Century. Procedia Computer Science, 25, 330-337. https://doi.org/10.1016/j.procs.2013.11.039.

[7] Lv, Z., Li, X. \& Li, W. 2017. Virtual Reality Geographical Interactive Scene Semantics Research for Immersive Geography Learning. Neurocomputing, 254, 1339-1351. https://doi.org/10.1016/j.neucom.2016.07.078.

[8] Makransky, G., Lilleholt, L. \& Aaby, A. 2017. Development and Validation of The Multimodal Presence Scale for Virtual Reality Environments: A Confirmatory Factor Analysis and Item Response Theory Approach. Computers in Human Behavior, 72, 276-285. https://doi.org/10.1016/j.chb.2017.02.066.

[9] Motamedi, A., Wang, Z., Yabuki, N., Fukuda, T. \& Michikawa, T. 2017. Signage Visibility Analysis and Optimization System Using BIM-Enabled Virtual Reality (VR) Environments. Advanced Engineering Informatics, 32, $248-262$. https://doi.org/10.1016/j.aei.2017.03.005.

[10] Rohani, A. 2014. Media Instruksional Edukatif. Jakarta: PT. Rineka Cipta.

[11] Rutten, N., Van Joolingen, W.R. \& Van Der Veen, J.T. 2012. The Learning Effects of Computer Simulations in Science Education. Computers and Education, 58(1), 136-153. https://doi.org/10.1016/j.compedu.2011.07.017.

[12] Sadiman, A.S. 2014. Media Pendidikan, Pengertian, Pengembangan dan Pemanfaatannya. Jakarta. PT. RajaGranfindo Persada.

[13] Smaldino, S.E., Deborah, L. \& James, D. 2014. Instructional Technology and Media for Learning. Jakarta: Kencana Prenadamedia Group.

[14] Sun, K. T., Lin, C.L. \& Wang, S.M. 2010. A 3-D Virtual Reality Model of The Sun and the Moon For E-Learning At Elementary Schools. International Journal of Science and Mathematics Education, 8(4), 689-710. https://doi.org/10.1007/s10763-009-9181-z.

[15] Thiagarajan, S., Semmel, D. \& Semmel, M.I. 1974. Instructional Development for Training Teachers of Exceptional Children. Indiana: Indiana University 